\title{
Empowerment Online: Feminist Adult Learning Strategies
}

\author{
Regina Juchun Chu \\ Center for Teacher Education, National Tsing Hua University, Hsinchu, Taiwan \\ Email: chu@mx.nthu.edu.tw
}

Received December 31 ${ }^{\text {st }}$, 2013; revised January 31 ${ }^{\text {st }}$, 2014; accepted February $7^{\text {th }}$, 2014

\begin{abstract}
Copyright (C) 2014 Regina Juchun Chu. This is an open access article distributed under the Creative Commons Attribution License, which permits unrestricted use, distribution, and reproduction in any medium, provided the original work is properly cited. In accordance of the Creative Commons Attribution License all Copyrights () 2014 are reserved for SCIRP and the owner of the intellectual property Regina Juchun Chu. All Copyright (C) 2014 are guarded by law and by SCIRP as a guardian.
\end{abstract}

\begin{abstract}
The purpose of this is to investigate how adult female learners constitute their perceptions of self and learning behavior in an internet learning environment-weblog. Based on previous qualitative research method and literature review, this study intended to develop and validate a feminist adult learning strategy scale (FALSS) to understand the women's learning strategy by applying weblogs. 417 valid data from the participants in two studies (exploratory and confirmatory factor analysis) were analyzed for the purpose. The results of these studies supported a 15-item, 4-factor FALSS: Empowerment Attempt, Sharing Experiences, Participatory Learning, and Critical Thinking and Open-Mindedness.
\end{abstract}

Keywords: Online Learning; Adult Learning; Feminist Education

\section{Introduction}

Weblogs (blogs) have recently drawn considerable attention as a new form of communication. Since the late 1990s, blogs have become a growing phenomenon. There were only 30,000 bloggers in 1998 (Amis, 2002). Recent survey found that the number of blog readers has skyrocketed to about 94 million American adults and that about half of Internet users read blog content (Technorati, 2008).

With the advent of Web2.0 technology, weblogs provided alterative media for individual learning and teaching. Apart from traditional education system, personal weblogs are more self-directed free from the space and time limit of class meeting. The asynchrony interactions of friends and self-initiated personal portfolio organized by the learners enable the social construct and transformation for the users. This student-centered learning environment (Gomaz, 2008) allows learners to actively reflect, organize and construct their own learning and theories especially for women. Women may possibly express themselves without restrictions of patriarchy structures derived from classroom interactions, texts, and knowledge contents (Hughes, 1995; Tisdell, 1993). However, a web-based feminist learning experience such as online discussion, self-expression, digital poster group, and weblogs may play another learning opportunity, and further develop female learners' leadership (Littlefield \& Roberson, 2005) and their transformation(Chu et al., 2012). Kelly, Pomerantz, \& Currie (2006) also found that young female learners will develop effective learning and survival strategies in this environment. Therefore, the purpose of this study is to develop and validate a scale that measures the learning strategies used by adult women when using weblogs.

Feminist education or called feminist pedagogy was introduced in 1980s. Feminist education starting from feminism challenges the knowledge and theories deducted from tradition- al Western cocasion male elites (Bunch, 1981; 2000). Feminist educators concern more about the history, experience and relationships, the way of knowing (Belenky, Clinchy, Golderberg, \& Tarule, 1986) that create a new identity of women.

Tisdell (1988) categorized three models of feminist education based on the study of Masher (1987): psychological models, structural models and postructural model. Psychological model developed based from literal feminism and psychiatry analysis. This model concerns the psychological needs of female learners; stresses the importance of gender need differences in learning environments and relationships. The model highlights individual caring and empowerment. The means to reach the goal of empowerment is by voice up, expressing and listening to herself. Structural model emphasizes the power structure and the nature of relationships. This model was derived from criticism and structural feminism. Relative to patriarchy structure, this feminist model take women as the oppressed who need to be emancipated. Post structural model was influenced by post modernism and post structural feminism stressing the relationships of power and identity. This model asserted that it is not enough to focus on structure, they need to understand the position. Positionality is the core of the model. The main issues of adult learning, then, are positionality, knowledge construction, voice up and power.

\section{Purpose of the Study}

The purpose of this study is to develop and validate a Feminist Adult Learning Strategy Scale (FALSS) for measuring the learning style and strategy used for women when they are writing and maintain their own weblogs. The results of this research will contribute to the study of adult self-directed learning studies to see how women transform and reposition themselves under a patriarchy society. 


\section{Method}

\section{Study 1: Pilot Test}

\section{Data Collection}

This study was based on feminist education for assessing women bloggers among Internet users. The data were collected from an online survey to attract female blog writers. This study applied a purposive sample to target Internet users who are going online for writing journals on weblogs on a daily base.

In order to draw female webloggers with a wide range of viewpoints, notices of the survey were posted on a wide range of Web sites, such as personal blogs, online discussion groups, and chat rooms. Defined as blogs dedicated to personal journal writing, commentaries, and analyses, a total of 200 female blog writers were selected. Survey responses were returned as data files, containing the data and time of receipt as well as the respondents' Internet survey addresses. Internet server and e-mail addresses were used to remove duplicate responses. A total of 182 female adult bloggers participated in this study and fill out the survey on line.

\section{Participants}

This study was based on feminist education for assessing women bloggers among Internet users. The data were collected from an online survey to attract female blog writers. This study applied a purposive sample to target Internet users who are going online for writing journals on weblogs on a daily base.

In order to draw female webloggers with a wide range of viewpoints, notices of the survey were posted on a wide range of Web sites, such as personal blogs, online discussion groups, and chat rooms. Defined as blogs dedicated to personal journal writing, commentaries, and analyses, a total of 200 female blog writers were selected. Survey responses were returned as data files, containing the data and time of receipt as well as the respondents' Internet survey addresses. Internet server and e-mail addresses were used to remove duplicate responses. A total of 182 female adult bloggers participated in this study and fill out the survey on line.

\section{Item Generation}

The process of item generation began with consulting the literature and empirical studies that examined indicators of feminist learning strategies and styles of women bloggers or blog readers rooted from feminist education theories. From the above literature review and prior qualitative studies, indicators could be groups into four categories: (a) empowerment attempt; (b) sharing experiences; (c) participatory learning; and (c) critical thinking and open-minded. A search for appropriate items was made from available sources that contained items to measure some or all of the above constructs, and they included bloggers as participants.

A list of 28 items was generated by the authors, all of which are university faculty members with earned PhDs in related disciplines. An important consideration at the item generation stage was to ensure that the items could be understood by the potential respondents. For this reason, focus group interviews with bloggers were conducted to determine the appropriateness of each item. In total, we conducted two focus group discussions, each with 6 and 7 individual bloggers. Based on the suggestions and recommendations given by the participants from the focus groups, the items were revised to achieve face validity, clarity in language, and parsimony in scale length. Moreover, focus group members were also based on their experience to generate some more items for the pilot. The focus group discussions resulted in the total number of items being reduced from 28 to 20 at this stage.

\section{Data Analysis}

Factor analysis was run to identify the learning strategies for women with their blogs. The 20 statements were factored by principal component analysis (PCA) with varimax rotation (orthogonal), which assigned the items to a specific factor when the primary loadings were greater than .50 .

\section{Result}

An exploratory factor analysis (EFA) using PCA with varimax rotation was conducted on the 20 items to explore the underlying structure of the scale. The criteria for determining the number of components to retain were Kaiswer's (1960) eigenvalue greater than 1 and Cattell's (1966) scree test. The initial solution yielded four components with eigenvalues exceeding 1 , accounting for a total of $63.58 \%$ of the variance. Inspection of the scree plot supported the retention of four components as well. Following the recommendations by Hair, Black, Babin and Anderson (2010), items with loadings greater than 0.50 have practical significance. On this basis, 15 of the 20 items were retained for further analysis. At this stage, the four factors were empowerment attempt (EA, 4 items), sharing experiences (SE, 4 items), participatory learning (PL, 4 items), critical thinking and open-mindedness (CO, 3 items). To provide further checks on the factor structure, a principal axis factor analysis with orthogonal and oblique rotations (direct oblimin: delta $=0$, promax: kappa $=4$ ) were conducted on the four-factor solution and these yielded consistent results. The descriptive statistical analyses show that the mean scores of all 15 items ranged from 3.21 to 4.22 . The standard deviations ranged from 0.52 to 0.97 and the skew and kurtosis indices from -0.78 to 0.23 and -0.79 to 1.74 respectively. Following Kline's (2005) recommendations, the data in this study were considered to be univariate normal (Table 1). Table 2 shows the varimax rotated solution and the results of the principal component analysis of the 15-item, 4-factor scale. Based on a literature review of typologies of feminist pedagogy studies, and sophisticated statistical analyses, general definitions of the four learning strategies for women bloggers in this study are as follows:

1) Empowerment attempt: Users have the attempt to pursue personal control and decision making authority.

2) Sharing experiences: Using blogs to share life experiences for personal use and discussions with others.

3) Participatory learning: Actively connect and construct personal knowledge by organize personal portfolio and discussing with learning peers.

4) Critical thinking and open-mindedness: Users conduct critical reflection on her own works and opinions provided by others.

\section{Study 2: Validation}

\section{Participants}

The purpose of this study is to assess the factorial validity of the 15-item FALSS. Participants in this study were 235 female bloggers in Taiwan. The mean age of the participants was 30.77 $(\mathrm{SD}=5.21)$. The sample comprised $143(60.85 \%)$ active fe- 
Table 1.

Descriptive of the 15 items proposed for the FALSS.

\begin{tabular}{cccccc}
\hline Item & Mean & SD & Skewness & Kurtosis & Range \\
\hline EA1 & 3.80 & 0.72 & -.67 & .67 & $2-5$ \\
EA2 & 3.74 & 0.85 & -.33 & -.42 & $2-5$ \\
EA3 & 3.74 & 0.76 & -.55 & .24 & $2-5$ \\
EA4 & 3.21 & 0.81 & -.15 & -.30 & $1-5$ \\
SE1 & 4.15 & 0.58 & -.42 & 1.74 & $2-5$ \\
SE2 & 4.12 & 0.58 & -.15 & .45 & $2-5$ \\
SE3 & 4.21 & 0.62 & -.16 & -.53 & $3-5$ \\
SE4 & 4.14 & 0.56 & -.12 & .63 & $2-5$ \\
PL1 & 4.18 & 0.52 & .23 & .23 & $3-5$ \\
PL2 & 4.18 & 0.59 & -.44 & 1.51 & $2-5$ \\
PL3 & 4.11 & 0.61 & -.29 & .63 & $2-5$ \\
PL4 & 4.22 & 0.56 & -.14 & .48 & $2-5$ \\
CO1 & 3.64 & 0.72 & -.28 & .34 & $1-5$ \\
CO2 & 3.27 & 0.97 & -.24 & -.79 & $1-5$ \\
CO3 & 3.68 & 0.89 & -.78 & .60 & $1-5$ \\
\hline
\end{tabular}

Table 2.

Rotated factor loadings, Crohbach's alpha and eigenvalues for the four factors of FALSS ${ }^{\mathrm{a}}$.

\begin{tabular}{|c|c|c|c|}
\hline Item & EA SE & PL & $\mathrm{CO}$ \\
\hline \multicolumn{4}{|l|}{$\begin{array}{l}\text { Factor 1: Empowerment Attempt (EA) } \\
\alpha=0.67 \text { eigenvalue }=13.68\end{array}$} \\
\hline $\begin{array}{l}\text { I have the power to decide who has the access to my } \\
\text { blog. }\end{array}$ & .82 & & \\
\hline I decide what to put on my personal journals. & .79 & & \\
\hline I feel I have the power in influencing people. & 79 & & \\
\hline I construct my own theory for my life. & .65 & & \\
\hline \multicolumn{4}{|l|}{$\begin{array}{l}\text { Factor 2: Sharing Experiences }(\mathrm{SE}) \\
\alpha=0.74 \text { eigenvalue }=22.07\end{array}$} \\
\hline $\begin{array}{l}\text { I write journals to let my friends know what happens to } \\
\text { me. }\end{array}$ & .80 & & \\
\hline I share my opinions through my blog. & .78 & & \\
\hline I share my photos by my blog. & .56 & & \\
\hline $\begin{array}{l}\text { I share my network with common } \\
\text { interests through my blog. } \\
\text { Factor 3: Participatory Learning (PL) } \\
\alpha=0.89 \text { eigenvalue }=15.55\end{array}$ & .52 & & \\
\hline I learn new ideas when discussing with my friends. & & .81 & \\
\hline I organize what to portray on my blog. & & .81 & \\
\hline $\begin{array}{l}\text { I compare and reconstruct the information from blog } \\
\text { connections. }\end{array}$ & & .80 & \\
\hline I demonstrate the work I have done on my blog. & & .74 & \\
\hline \multicolumn{4}{|l|}{$\begin{array}{l}\text { Factor 4: Critical Thinking and Open-Mindedness (EA) } \\
\alpha=0.86 \text { eigenvalue }=12.78\end{array}$} \\
\hline $\begin{array}{l}\text { I reflect what I have been from my } \\
\text { journals. }\end{array}$ & & & .65 \\
\hline $\begin{array}{l}\text { I rethink what I can do better by going through my blog } \\
\text { journals. }\end{array}$ & & & .62 \\
\hline I criticize other's opinions before I accept them. & & & .57 \\
\hline
\end{tabular}

${ }^{a}$ The scale internal consistency reaches .88 . male blog writers. All participants were volunteers and were not grant by extra points for grade or monetary reward.

\section{Confirmatory Factor Analysis}

The confirmatory factor analysis (CFA) of this study was used to examine the factorial structure of the 15-item scale and LISREL 8.8 was employed as the computer software for the analysis. The model examined in this study was tested using maximum likelihood estimation (ML). The model fit assessed by six indices: $\chi^{2}$, as the $\chi^{2}$ is sensitive to sample size, the ratio of $\chi^{2}$ to its degree of freedom $\left(\chi^{2} / d f\right)$ was used, with a recommended value smaller than 5.0. (Hu \& Bentler, 1999). Two absolute fit indices are reported as the standardized root mean square residual (SRMR) with a recommended value smaller than .05; and the root mean square error of approximation (RMSEA) with values less than .08 as acceptable fit (MacCallum, Browne, \& Sugawara, 1996). Finally, the comparative fit index (CFI) and non-normed fit indix (NNFI) with a recommended value larger than .95 (Hu \& Bentler, 1999) to indicate an acceptable level of model fit.

\section{Results}

The model fit of the facto model reveals a good model fit $\left(\chi^{2}\right.$ $=234.62, \mathrm{df}=84 ; \chi^{2} / d f=2.79 ; \mathrm{NNFI}=0.98 ; \mathrm{GFI}=0.95$; RMSEA $=0.067$; SRMR $=.039$ ). As each indicator was specified to load on just one latent variable in the model, the standardized estimates were regarded as structure coefficients that estimate indicator-construct correlations (Kline, 2005).

For the good model fit indices, composite reliability and average variance extracted reach the acceptable level, which provided support for convergent validity (Maruyama, 1998). The inter-factor correlations $(\Phi)$ are between .54 to .69 , all smaller than the square root of AVE of each construct, indicating a good discriminant validity. In addition, all standardized estimates had exceeded the recommended value of .50 (Hair et al., 2010). The Cronbach's alpha for the instrument is .88 and the $\alpha$ for the four subscale are $.67, .74, .89, .86$ respectively. The factor loading coefficients, t-value for each item and composite reliability, average variance extracted of each construct are shown in Table 3.

\section{Discussion and Conclusion}

The factor structure of the FALSS was validated in this study. The four dimensions of how women learn on their own personal weblogs are empowerment attempt, sharing experiences, participatory learning, and critical thinking and open-mindedness. The result was derived from a sample comprised participants mainly from Taiwan. From the view of diversity, the result may provide a start for the future studies applying in different culture and ethnic groups. For this sample, critical thinking was scored the lowest while participatory learning scored the highest. It echoes the finding of collectivism that Eastern culture value higher on the relationships rather than criticism (Chu \& Chu, 2010). This scale will contribute the knowledge of adult online learning by combining other adult learning strategies such as self-directed learning readiness, collaborative learning, and their epistemological development to move their comfortable space of knowing to uncomfortable places of becoming (Philips, Harris, Larson, \& Higgins, 2009). 
Table 3.

Factor loading coefficients, t-value, CR and AVE of FALSS.

\begin{tabular}{ccccc}
\hline Item & $\lambda$ & t-value & CR $^{\mathrm{a}}$ & $\mathrm{AVE}^{\mathrm{b}}$ \\
\hline EA1 & .52 & 6.44 & & \\
EA2 & .59 & 6.91 & .73 & .51 \\
EA3 & .66 & 9.27 & & \\
EA4 & .77 & 10.48 & & \\
SE1 & .64 & 11.57 & & .62 \\
SE2 & .75 & 9.63 & & \\
SE3 & .71 & 10.88 & .77 & .68 \\
SE4 & .60 & 8.32 & & \\
PL1 & .80 & 14.16 & & .67 \\
PL2 & .85 & 15.75 & & \\
PL3 & .85 & 14.16 & & \\
PL4 & .80 & 15.59 & & \\
CO1 & .71 & 10.12 & & \\
CO2 & .90 & 15.79 & .86 & \\
CO3 & .84 & 14.39 & & \\
\hline
\end{tabular}

${ }^{\mathrm{a}} \mathrm{CR}$ refers to the composite reliability, recommended value is $>.70$; ${ }^{\mathrm{b}} \mathrm{AVE}$ refers to the average variance extracted, recommended value is $>.50$.

\section{Acknowledgements}

Funding of this research work was supported by National Science Council, Taiwan, under Grant Number 99-2511-S-011003-MY2 and 101-2511-S-007 -003 -MY2.

\section{REFERENCES}

Amis, D. (2002). Web logs: Online navel gazing? http://www.netfreedom.Org/news.asp?item=190

Belenky, M., Clinchy, B., Golderberg, N., \& Tarule, J. (1986). Women's ways of knowing. New York: Basic Books.

Bunch, C., \& Frost, S. (2000). "Empowerment," and “Women's $\mathrm{Hu}$ man Right”. New York, NY: Routledge International Encyclopedia of Women's Studies.

Bunch, C. (1981). Building feminist theory: Essays from quest, edited with Flax, Freeman, Hartsock, and Mautner. New York, NY: Longman Inc.

Cattell, R. B. (1966). The scree test for the number of factors. Multivariate behavioral Research, 1, 245-276. http://dx.doi.org/10.1207/s15327906mbr0102_10

Chu, R. J., \& Chu, A. Z. (2010). Multi-level analysis of peer support, Internet self-efficacy and e-learning outcomes: The contextual effects of collectivism and group potency. Computers \& Education, 55, 145154. http://dx.doi.org/10.1016/j.compedu.2009.12.011

Chu, R. J., Chu, A. Z., Weng, C., Tsai, C.-C., \& Lin, C. (2012). Transformation for adults in an Internet-based learning environment-Is it necessary to be self-directed? British Journal of Educational Technology, 43, 205-216. http://dx.doi.org/10.1111/j.1467-8535.2010.01166.x

Gomez, D. S. (2008). Women's proper place and student-centered pedagogy. Studies in Philosophy and Education, 27, 313-333. http://dx.doi.org/10.1007/s11217-007-9048-0

Hair, Jr., J. E., Black, W. C., Babin, B. J., \& Anderson, E. (2010). Multivariate data analysis. 7th Edition, Upper Saddle River, New Jersey: Prentice-Hall.

Hu, L., \& Bentler, P. M. (1999). Cutoff criteria for fit indexes in covariance structure analysis: Conventional criteria versus new alternatives. Structural Equation Modeling, 6, 1-55. http://dx.doi.org/10.1080/10705519909540118

Hughes, K. P. (1995). Feminist pedagogy and feminist epistemology: An overview. International Journal of Lifelong Education, 14, 214230. http://dx.doi.org/10.1080/0260137950140303

Kaiser, H. F. (1960). The application of electronic computers to factor analysis. Educational and Psychological Measurement, 20, 141-151. http://dx.doi.org/10.1177/001316446002000116

Kelly, D. M., Pomerantz, S., \& Currie, D. H. (2006). "No boundaries”? Girls' interactive, online learning about femininities. Youth \& Society, 38, 3-28. http://dx.doi.org/10.1177/0044118X05283482

Kline, R. B. (2005). Principles and practice of structural equation modeling. 2nd Edition, New York: The Guilford Press.

Littlefield, M. B., \& Roberson, K. R. C. (2005). Computer technology for the feminist classroom. Affilia-Journal of Women and Social Work, 20, 186-202. http://dx.doi.org/10.1177/0886109905274676

MacCallum, R. C., Browne, M. W., \& Sugawara, H. M. (1996). Power analaysis and determination of sample size for covariance structure modeling. Psychological Methods, 1, 130-149. http://dx.doi.org/10.1037/1082-989X.1.2.130

Maher, F. A., \& Tetreault, M. (1994). The feminist classroom. New York: Basic Books.

Maruyama, G. M. (1988). Basics of structural equation modeling. Thousand Oaks, CA: Sage.

Masher, F. A. (1987). Toward a richer theory of feminist pedagogy: A comparison of "liberation" and "gender" models for teaching and learning. Journal of Education, 169, 91-100.

Phillips, D. K., Harris, G., Larson, M. L., \& Higgins, K. (2009). Trying on-being in-becoming four women's journey(s) in feminist poststructural theory. Qualitative Inquiry, 15, 1455-1479. http://dx.doi.org/10.1177/1077800409347097

Technorati (2008). State of the blogosphere report. http://technorati.com/blogging/state-of-the-blogosphere.

Tisdell, E. J. (1993). Interlocking systems of power, privilege, and oppression in adult higher education classes. Adult Education Quarterly, 43, 203-226. http://dx.doi.org/10.1177/0741713693043004001 